OPEN ACCESS

Edited by: Ursula Werneke,

Umeå University, Sweden

Reviewed by:

Konstantinos Kotsis,

University of loannina, Greece

Roger C. Ho,

National University of Singapore,

Singapore

${ }^{*}$ Correspondence:

Jin-San Zhang

Zhang_Jinsan@wmu.edu.cn

Xiao-Kun L

Xiaokunli@wmu.edu.cn

${ }^{\text {t}}$ These authors have contributed equally to this work

Specialty section: This article was submitted to Public Mental Health, a section of the journal

Frontiers in Psychiatry

Received: 19 May 2020 Accepted: 26 June 2020

Published: 08 July 2020

Citation:

Chen K-Y, Li T, Gong F-H, Zhang J-S and Li X-K (2020) Predictors of HealthRelated Quality of Life and Influencing Factors for COVID-19 Patients, a Follow-Up at One Month. Front. Psychiatry 11:668. doi: 10.3389/fpsyt.2020.00668

\section{Predictors of Health-Related Quality of Life and Influencing Factors for COVID-19 Patients, a Follow-Up at One Month}

\author{
Ke-Yang Chen ${ }^{1+}$, Ting $\mathrm{Li}^{2+}$, Fang-Hua Gong ${ }^{3}$, Jin-San Zhang ${ }^{3,4^{*}}$ and Xiao-Kun $\mathrm{Li}^{3^{*}}$ \\ 1 Department of Neurology, The Second Affiliated Hospital and Yuying Children's Hospital of Wenzhou Medical University, \\ Wenzhou, China, ${ }^{2}$ Department of Anesthesia and Critical Care, and Clinical Research Unit, The Second Affiliated Hospital \\ and Yuying Children's Hospital of Wenzhou Medical University, Wenzhou, China, ${ }^{3}$ School of Pharmaceutical Sciences, \\ Wenzhou Medical University, Wenzhou, China, ${ }^{4}$ Institute of Life Sciences, Wenzhou University, Wenzhou, China
}

Objective: To survey the health-related quality of life ( $H R Q \mathrm{~L})$ and its influencing factors among patients with COVID-19 in their first medical follow up.

Methods: All patients diagnosed with COVID-19 were discharged from 12 hospitals in Wenzhou, Zhejiang from Jan 17, 2020 to Mar 20, 2020. Prospectively collected and analyzed data included demographics, clinical symptoms, comorbidity, and chest CT imaging features at the first follow up, 1 month after discharge. All patients underwent the HRQoL evaluation with the Chinese version of Short-Form 36-item questionnaire (SF-36) as well as a general condition questionnaire. Factors associated with SF-36 were constructed using linear regression. Predictors of impaired physical component summary (PCS) and a mental component summary (MCS) were identified by logistic regression.

Results: SF-36 demonstrated a significant difference in HRQoL in patients with COVID19, except in physical function (PF), when compared to the general Chinese population $(p<0.05)$. The multiple linear regressions demonstrated that age was negatively associated with $\mathrm{PF}$, role physical $(\mathrm{RP})$, but positively associated with vitality (VT) $(p<0.05)$. PF, bodily pain (BP), and role-emotional (RE) were negatively associated with the female sex $(p<0.05)$. For mental health, the clinical subtypes were significant associated factors $(p<0.05)$. Length of stay (LOS) was strongly negatively associated with $\mathrm{RE}$ and $\mathrm{RP}$, and positively associated with $\mathrm{VT}(p<0.05)$. Logistical regression revealed that non-obese overweight (OR 3.71) and obesity (OR 3.94) were risk factors for a low PCS and female sex (OR 2.22) was a risk factor for a low MCS.

Conclusions: Health-related quality of life was poor among COVID-19 patients at the 1 month follow-up. Patients suffered from significant physical and psychological impairment. Therefore, prospective monitoring of individuals exposed to SARS-CoV-2 is needed in order to fully understand the long-term impact of COVID-19, as well as to inform prompt and efficient interventions to alleviate suffering.

Keywords: COVID-19, health-related quality of life, SF-36, follow-up, influencing factors 


\section{INTRODUCTION}

The coronavirus disease 19 (COVID-19) is an infectious disease caused by the relentless spread of the severe acute respiratory coronavirus 2 (SARS-CoV-2) from human to human, all across the world (1). In the early stages of this disease, severe acute respiratory infection symptoms frequently occur (2). Some patients rapidly develop acute respiratory distress syndrome (3), and other serious complications. In addition to the pulmonary system, COVID-19 can impact multiple other organ systems, including neurological (4), cardiovascular (5), hematopoietic (6), and psychological (7). Our understanding is evolving regarding the threats COVID-19 poses to patient quality of life, mental health and life expectancy (8).

Along with social progress and the transformation of medical care and service systems, interest in health-related quality of life (HRQoL) is increasing (9). HRQoL is defined as the subjective feeling by patients of the multifaceted effect of a disease (10). The Short-Form 36-item questionnaire (SF-36) is a popular instrument for evaluating HRQoL (11). However, no study to date has explored the psychometric performance and applicability of a Chinese version of SF-36 in assessing HRQoL in COVID-19 patients at first month follow up.

Wenzhou is located in the southeastern coast of China, which has a population of 9.3 million. Wenzhou was initially one of the worst hit cities out of Hubei Province with 504 confirmed cases due to the highest volume of mobility with Wuhan $(12,13)$. The objective of this study was to provide theoretical basis for the targeted development of measures to improve quality of life of patients with COVID-19, as well as to guide relevant governmental departments and to improve medical and health care service strategy in the future.

\section{METHODS}

\section{Study Design and Participants}

This is a multicenter and cross-sectional study of patients with COVID-19 who were discharged from Jan 17, 2020 to Mar 20, 2020 at first month follow up from twelve hospital isolation wards in Wenzhou City, Zhejiang Province, China. The diagnosis of COVID-19 was based on the Chinese standard at the time (14). All patients had subsequent laboratory confirmation of SARS-CoV-2. Patients with SARS-CoV-2 infection were clinically divided into four types: mild, moderate, severe, and critical, according to a WHO-China Joint Mission report on COVID-19.

\section{Questionnaire Development}

The questionnaire contains questions with defined response categories. A few questions asked participants to provide descriptive information. Participants were informed of the purpose, the agency conducting the research, and the privacy

\footnotetext{
Abbreviations: BP, bodily pain; GH, general health; HT, health transition; MCS, mental component summary; $\mathrm{MH}$, mental health; PCS, physical component summary; PF, physical function; RE, role-emotional; RP, role physical; SF, social functioning; VT, vitality.
}

protection of survey. The study was approved by the Institutional Review Board of Wenzhou Medical University. Written informed consent was obtained from all participants.

\section{SF-36 Scores on the Evaluation of HRQoL}

The Chinese version of the SF-36 was translated from the International Quality of Life Assessment (IQOLA) SF-36 Standard UK Version 1.0 (15), composed of a single item of health transition (HT) and 35 items, which can be divided into 8 subscales: (1) physical function (PF), limitations due to physical health problems (role physical, RP), (3) bodily pain (BP), (4) general health $(\mathrm{GH}),(5)$ vitality (VT), (6) social functioning (SF), (7) limitations due to emotional health problems (roleemotional, RE), and (8) mental health. The scores of SF-36 between 0 and 100 were assigned to each domain, with higher scores indicating more favorable functional status. The eight subdomain scores were aggregated into two summary measures: physical component summary (PCS) scores and mental component summary (MCS) scores, while a low MCS or PCS $(<50)$ is indicative of a poor HRQoL (16).

\section{Chinese Population Norm}

The Chinese population norm was based on the study done by $\mathrm{He}$ and colleagues (17). A random sample of Chinese adults in mainland China was collected and analyzed.

\section{Statistical Analysis}

Descriptive statistics for demographic information were calculated. The results were expressed as either the mean \pm standard deviation (SD) or the categorical data were summarized as percentage of the total group. Differences in quantitative data distributions between patient subgroups were tested by Student's t-test for normally distributed data and by Wilcoxon rank-sum test or Kruskal-Wallis test for non-normally distributed data. Linear regression analysis was performed to explore the correlation between two variables. Logistic regression analysis was used to determine factors associated with decreased PCS score and MCS score. A $p$-value threshold of $<0.05$ was considered statistically significant. All statistical analyses were performed using SPSS software (SPSS Inc, USA).

\section{RESULTS}

\section{Demographic and Clinical Characteristics of the Patients}

Five hundred and four COVID-19 patients were enrolled in this cohort study. Among the 503 survivors, 131 did not follow up and 11 provided incomplete data. A total of 361 participants were available for analysis. Baseline characteristics of the participants were collected (Table 1). The study participants included 186 men (51.5\%) and 175 women (48.5\%), with 327 mild cases and 34 severe cases. The mean age (SD) was 47.22 years (13.03) and more than half of these patients were age 40 to 60 years. The mean body mass index (BMI) was 23.64 (3.31) and the mean LOS (SD) in hospital was 19.13 days (7.60). 
TABLE 1 | Socio-demographic characteristics and health situation of the study sample.

\begin{tabular}{|c|c|c|c|}
\hline Characteristics & Subtype & Number & $\begin{array}{c}\text { Percentage } \\
(\%)\end{array}$ \\
\hline \multirow[t]{2}{*}{ Sex } & Male & 186 & 51.5 \\
\hline & Female & 175 & 48.5 \\
\hline \multirow[t]{2}{*}{ Subgroup } & Mild & 327 & 90.6 \\
\hline & Severe & 34 & 9.4 \\
\hline Age, years; mean (SD) & 47.22(13.03) & & \\
\hline BMI & 23.64(3.31) & & \\
\hline Heart rate, (bpm) & $86.63 \pm 12.8$ & & \\
\hline $\begin{array}{l}\text { Systolic blood pressure, } \\
(\mathrm{mmHg})\end{array}$ & $130.91 \pm 17.17$ & & \\
\hline $\begin{array}{l}\text { Diastolic blood pressure, } \\
(\mathrm{mmHg})\end{array}$ & $82.97 \pm 11.14$ & & \\
\hline Length of stay (LOS) & $19.13(7.60)$ & & \\
\hline \multirow[t]{8}{*}{ Age } & $10-19$ & 6 & 1.7 \\
\hline & $20-29$ & 29 & 8.0 \\
\hline & 30-39 & 67 & 18.6 \\
\hline & $40-49$ & 106 & 29.3 \\
\hline & $50-59$ & 93 & 25.8 \\
\hline & $60-69$ & 44 & 12.2 \\
\hline & $70-79$ & 13 & 3.6 \\
\hline & 80-89 & 3 & 0.8 \\
\hline \multirow[t]{2}{*}{ Smoking } & Yes & 17 & 4.7 \\
\hline & No & 344 & 95.3 \\
\hline \multirow[t]{2}{*}{ Drinking } & Yes & 15 & 4.2 \\
\hline & No & 346 & 95.8 \\
\hline \multirow[t]{2}{*}{ Chronic diseases history } & Yes & 115 & 31.9 \\
\hline & No & 246 & 68.1 \\
\hline
\end{tabular}

\section{Scores of SF-36 in the Study}

The SF-36 mean score for eight specific dimensions was measured (Figure 1). In these eight dimensions, RP, SF, and $\mathrm{RE}$ subgroup scores were significantly lower in patients than the Chinese population norm $(p<0.05)$. However, the scores of BP, $\mathrm{GH}, \mathrm{VT}$, and $\mathrm{MH}$ were higher than the norm group $(p<0.05)$. Furthermore, there was no difference between two groups in PF score $(p=0.75)$. At baseline, the mean scores were $55.96 \pm 7.24$

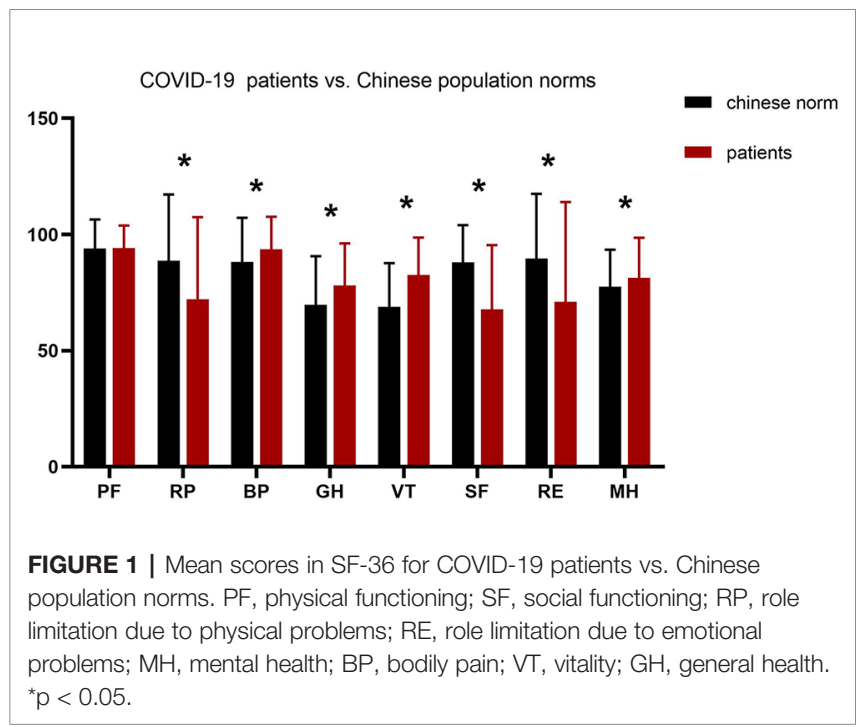

points for the PCSs and $48.92 \pm 10.81$ points for the MCSs, respectively. Comparison of HRQoL outcomes between COVID19 patients and subjects with normal health of the different sexes was performed (Table 2). Compared with normative group, RP, $\mathrm{SF}$, and RE subgroup scores were lower in the male group than the female group $(p<0.01)$. In contrast, the scores of $\mathrm{BP}, \mathrm{MH}$, $\mathrm{GH}$, and VT were higher than the normal group $(p<0.01)$. However, no significant differences were observed between the two groups in $\mathrm{PF}(p=0.43, p=0.41)$.

\section{Factors Associated With SF-36 Among Patients in the Multivariate Linear Regression}

Multivariate linear regression analysis was used to identify factors related to HRQoL of the follow-up cohort (Table 3). Age was negatively associated with PF, RP, but positively associated with VT $(p<0.05)$. PF, BP, and RE were negatively associated with the female sex $(p<0.05)$. The severity of the clinical subtype was significantly negatively associated with the $\mathrm{PF}, \mathrm{GH}, \mathrm{RE}$, and MH $(p<0.05)$. Length of stay (LOS) was negatively associated with RE and RP, and positively associated with VT $(p<0.05)$. In addition, there were significant negative association between lung function parameters (Forced vital capacity, FVC) and $\mathrm{MH}(P<0.05)$.

TABLE 2 | Comparison of health-related quality of life (HRQoL) outcomes between COVID-19 patients and subjects with normal health in different sex.

\begin{tabular}{|c|c|c|c|}
\hline Scale & Sample & Mean \pm SD & $\boldsymbol{P}$ \\
\hline \multirow[t]{4}{*}{ PF } & Male(n=186) & $95.13(9.11)$ & 0.43 \\
\hline & Norm & $95.60(10.43)$ & \\
\hline & Female $(\mathrm{n}=175)$ & $93.17(10.26)$ & 0.41 \\
\hline & Norm & $92.57(13.88)$ & \\
\hline \multirow[t]{4}{*}{$\mathrm{RP}$} & Male(n=186) & $71.37(34.73)$ & $<0.001$ \\
\hline & Norm & $90.76(26.09)$ & \\
\hline & Female $(n=175)$ & $72.29(36.40)$ & $<0.001$ \\
\hline & Norm & 86.99(30.41) & \\
\hline \multirow[t]{4}{*}{$\mathrm{BP}$} & Male(n=186) & $95.59(10.36)$ & $<0.001$ \\
\hline & Norm & $89.77(17.95)$ & \\
\hline & Female $(n=175)$ & $91.95(16.49)$ & $<0.001$ \\
\hline & Norm & $86.73(19.84)$ & \\
\hline \multirow[t]{4}{*}{$\mathrm{GH}$} & Male(n=186) & $78.31(17.37)$ & $<0.001$ \\
\hline & Norm & $71.20(20.03)$ & \\
\hline & Female $(n=175)$ & $77.80(19.01)$ & $<0.001$ \\
\hline & Norm & $68.41(21.68)$ & \\
\hline \multirow[t]{4}{*}{$\mathrm{VT}$} & Male(n=186) & 83.25(16.13) & $<0.001$ \\
\hline & Norm & $70.69(17.97)$ & \\
\hline & Female $(n=175)$ & $81.80(16.32)$ & $<0.001$ \\
\hline & Norm & $67.30(19.36)$ & \\
\hline \multirow[t]{4}{*}{ SF } & Male(n=186) & $70.44(27.68)$ & $<0.001$ \\
\hline & Norm & 88.39(16.20) & \\
\hline & Female $(n=175)$ & 64.66(27.16) & $<0.001$ \\
\hline & Norm & $87.71(15.82)$ & \\
\hline \multirow[t]{4}{*}{ RE } & Male(n=186) & $74.53(40.54)$ & $<0.001$ \\
\hline & Norm & $91.12(26.06)$ & \\
\hline & Female $(n=175)$ & $66.64(45.62)$ & $<0.001$ \\
\hline & Norm & $88.15(29.52)$ & \\
\hline \multirow[t]{4}{*}{$\mathrm{MH}$} & Male(n=186) & $81.27(17.46)$ & $<0.001$ \\
\hline & Norm & $77.80(15.78)$ & \\
\hline & Female $(n=175)$ & $81.24(17.37)$ & $<0.001$ \\
\hline & Norm & $77.43(17.42)$ & \\
\hline
\end{tabular}


TABLE 3 | Factors associated with Short-Form 36-item questionnaire (SF-36) among patients in the multivariate analysis.

\begin{tabular}{llccc}
\hline $\begin{array}{l}\text { Dependent } \\
\text { Variable }\end{array}$ & \multicolumn{1}{c}{$\begin{array}{c}\text { Independent } \\
\text { Variable }\end{array}$} & $\boldsymbol{P}$ & Beta & $\mathbf{9 5 \%} \mathbf{C l}$ \\
\hline $\mathbf{P F}$ & Age & $<0.001$ & -0.231 & $-0.250,-0.097$ \\
& Female & 0.033 & -0.107 & $-3.999,-0.174$ \\
RP & Clinical subtype & 0.001 & -0.175 & $-9.198,-2.442$ \\
& Chronic kidney & 0.005 & -0.147 & $-118.331,-21.661$ \\
& disease & & & \\
BP & Length of stay (LOS) & 0.004 & -0.149 & $-1.167,-0.221$ \\
GH & Age & 0.038 & -0.107 & $-0.571,-0.016$ \\
VT & Female & 0.013 & -0.131 & $-6.454,-0.773$ \\
& Clinical subtype & 0.042 & -0.107 & $-13.067,-0.233$ \\
SF & Age & 0.004 & 0.128 & $0.032,0.289$ \\
RE & Length of stay (LOS) & 0.040 & 0.113 & $0.023,0.461$ \\
& NA & NA & NA & NA \\
& Length of stay (LOS) & 0.002 & -0.163 & $-1.515,-0.357$ \\
& Clinical subtype & 0.014 & -0.128 & $-33.852,-3.920$ \\
MH & Female & 0.043 & -0.105 & $-17.774,-0.282$ \\
& Smoking history & 0.022 & -0.119 & $-1.515,-0.357$ \\
& Clinical subtype & 0.022 & -0.120 & $-13.045,-1.012$ \\
& FVC & $<0.001$ & -0.223 & $-0.052,-0.019$ \\
\hline & & & &
\end{tabular}

\section{Risk Factors for Low Health-Related Quality of Life}

We stratified patients into two groups according to the PCS and MCS with a cutoff point of 50 and then explored the relationship between the PCS, MCS, and potential risk factors (Tables 4 and 5). Logistic regression analysis demonstrated that being overweight (OR 3.71, 95\% CI 1.42-9.70) or obese (OR 3.94, 95\% CI 1.47-10.52) were significant factors associated with a poor PCS score. Female sex (OR 2.22, 95\% CI 1.30-3.81) was a significant determinant associated with an MCS $<50$ in COVID-19 patients.

TABLE 4 | Logistic regression analysis of COVID-19 patients with a physical component summary (PCS) $<50$.

\begin{tabular}{|c|c|c|c|}
\hline & & \multicolumn{2}{|c|}{ Multivariate logistic regression results } \\
\hline & & OR [95\% Cl] & $p$ value \\
\hline \multirow[t]{3}{*}{ Age } & $<45$ & 1 & \\
\hline & $45 \sim 60$ & $2.22[0.68,7.17]$ & 0.184 \\
\hline & $>60$ & $0.87[0.34,2.27]$ & 0.780 \\
\hline \multirow[t]{2}{*}{ Sex } & Male & 1 & \\
\hline & Female & $1.84[0.87,1.91]$ & 0.110 \\
\hline \multirow[t]{3}{*}{ BMI } & Normal & $0.70[0.16,2.99]$ & 0.625 \\
\hline & Overweight & $3.71[1.42,9.70]$ & 0.008 \\
\hline & Obesity & $3.94[1.47,10.52]$ & 0.006 \\
\hline \multirow[t]{2}{*}{ Clinical subtype } & Mild & 1 & \\
\hline & Server & $1.49[0.55,4.00]$ & 0.434 \\
\hline LOS & & $1.00[0.96,1.04]$ & 0.911 \\
\hline FEV1 & & $0.68[0.36,1.29]$ & 0.235 \\
\hline FVC & & $1.00[0.94,1.08]$ & 0.925 \\
\hline FEV1/FVC & & $1.03[0.99,1.06]$ & 0.132 \\
\hline \multirow[t]{2}{*}{ Smoking } & No & 1 & \\
\hline & Yes & $0.37[0.05,2.60]$ & 0.319 \\
\hline \multirow[t]{2}{*}{ Drinking } & No & 1 & \\
\hline & Yes & $3.25[0.74,14.28]$ & 0.118 \\
\hline \multirow[t]{2}{*}{ Hypertension } & No & 1 & \\
\hline & Yes & $1.08[0.48,2.45]$ & 0.851 \\
\hline \multirow[t]{2}{*}{ Diabetes } & No & 1 & \\
\hline & Yes & $1.92[0.68,5.42]$ & 0.217 \\
\hline
\end{tabular}

TABLE 5 | Logistic regression analysis of COVID-19 patients with a mental component summary (MCS) $<50$.

\begin{tabular}{|c|c|c|c|}
\hline & & \multicolumn{2}{|c|}{ Multivariate logistic regression results } \\
\hline & & OR $[95 \% \mathrm{Cl}]$ & p value \\
\hline \multirow[t]{3}{*}{ Age } & $<45$ & 1 & \\
\hline & $45 \sim 60$ & $0.98[0.44,2.20]$ & 0.957 \\
\hline & $>60$ & $1.18[0.58,2.41]$ & 0.641 \\
\hline \multirow[t]{2}{*}{ Sex } & Male & 1 & \\
\hline & Female & $2.22[1.30,3.81]$ & 0.005 \\
\hline \multirow[t]{3}{*}{ BMI } & Normal & 1 & \\
\hline & Overweight & $1.14[0.51,2.55]$ & 0.751 \\
\hline & Obesity & $1.26[0.56,2.87]$ & 0.579 \\
\hline \multirow[t]{2}{*}{ Clinical subtype } & Mild & 1 & \\
\hline & Severe & $1.70[0.76,3.78]$ & 0.225 \\
\hline Length of stay (LOS) & & $0.61[0.27,1.36]$ & 0.125 \\
\hline FEV1 & & $0.79[0.53,1.27]$ & 0.364 \\
\hline FVC & & $1.00[0.96,1.04]$ & 0.860 \\
\hline FEV1/FVC & & $1.02[0.99,1.05]$ & 0.276 \\
\hline \multirow[t]{2}{*}{ Smoking } & No & 1 & \\
\hline & Yes & $2.16[0.67,6.89]$ & 0.195 \\
\hline \multirow[t]{2}{*}{ Drinking } & No & 1 & \\
\hline & Yes & $0.54[0.16,1.85]$ & 0.329 \\
\hline
\end{tabular}

\section{DISCUSSION}

The COVID-19 pandemic is a significant psychological and physiological stressor for individuals, as well as organizations across social and economic communities worldwide. This study is the first to perform a comprehensive analysis of HRQoL in Chinese COVID-19 patients in a 1-month follow-up cohort.

In this study, we examined the absolute difference between COVID-19 patients and a normal Chinese population in SF-36 scores, including male and female subsets. Patients had higher body pain and vitality scores, but lower physiological function, social function, and role-physical scores. To our knowledge, the COVID-19 patients had uncommon symptoms, including headache, abdominal pain, and chest pain, especially in the severe/critical group (18). Therefore, the physical pain caused by the COVID-19 may last for 1 month. Furthermore, during the acute phase of the disease, patients were quarantined in hospital wards and followed strict control measures (19). They had to reduce their connection with the community. Meanwhile, they focused more on themselves and less on the individuals around them, as well as social affairs, leading to lower SF scores. These findings could be applicable to infectious disease outbreaks for informing psychosocial factors important to long-term recovery.

Multivariate analysis demonstrated that the clinical subtype was negatively correlated with $\mathrm{PF}, \mathrm{GH}, \mathrm{RE}$, and $\mathrm{MH}$. This phenomenon demonstrated that the more severe the condition of patients, the more severe the impact on physical health, as well as emotional and mental health, after hospital discharge. The results are not surprising as-in addition to the physical and psychological impairment-the long period of isolation, fear of illness, and extreme uncertainty during the COVID-19 illness had tremendous psychological and mood disturbances, such as insomnia, irritability, and anger. Recent studies observed that during the early stage of the COVID-19 outbreak, patients were 
at higher risk for mental health issues than the general population $(20,21)$. Nevertheless, the neuropsychiatric mechanism of this pandemic is currently unknown. In the brain, contiguous spread from the nasopharyngeal mucosa or a hematogenous route are two major entry pathways of SARSCoV-2 into the CNS (22), as upper airway epithelium and vascular endothelium express Angiotensin Converting Enzyme 2 receptor (23). In addition, viruses undergo retrograde axonal transport to reach the neuron cell bodies or infecting endothelial cells of the blood-brain-barrier, epithelial cells of the bloodcerebrospinal fluid barrier in the choroid plexus (24). The breadth of this pandemic will likely require closer examination of the mechanisms underlying post-viral neuropsychiatric sequelae. Physical activity and exercise have been proven to be an effective method for directly improving both mental and physical health in general (25). Thus, COVID-19 patients with chronic diseases could also benefit from exercise.

Further subgroup analysis helped us identify patients with decreased quality of life. The PCS and MCS have been reported using norm-based scoring (mean 50 and SD 50) in nearly every published study to date (26). In our study, we found $15.5 \%$ of patients displayed poor physical health and $48.5 \%$ demonstrated poor mental health (scores <50). Multivariate logistical regression was performed to examine whether some factors were possible predictors of decreased PCS or MCS scores in SF-36. Overweight and obesity were predictors of PCSs lower than 50, indicating an association between BMI and impaired physical function. Early studies have demonstrated a similar association between increasing BMI and worse PCS scores (27, 28). BMI may influence HRQoL independent of related diseases (29). Therefore, BMI management is also crucial for the longterm rehabilitation of COVID-19. Moreover, female sex was a predictor of MCSs lower than 50, suggesting that female sex is a risk factor for the mental health quality of life in Chinese COVID-19 patients. Males and females have unique social roles and pressures, with different impacts on their disease course. Females take more care of family than males and need more energy to face stress, which results in a substantial emotional harm (30). Consequently, we argue that women are a concern in COVID-19 and should be considered for potential need for longer rehabilitation times. These findings could be applicable to infectious disease outbreaks for informing psychosocial factors important to long-term recovery. Psychotherapy such as cognitive behavior therapy and mindfulness therapy may improve the mental health of COVID-19 patients.

This study has several limitations. (1) This study may be biased due to relatively mild disease. Milder illness may correlate with higher quality of life and cause an overestimate of HRQoL. (2) Another limitation is that the study population did not include children, which should be investigated further in future research. (3) Furthermore, investigation of the physical and mental health of COVID-19 patients should include more specific, comprehensive evaluation tools, such as the Quality of Life Enjoyment and Satisfaction Questionnaire, Hamilton Anxiety Scale, and Hamilton Depression Scale, which may add to the accuracy of assessment of mental health status. (4) Finally, the cross-sectional nature of the data precludes making causal inferences.

\section{CONCLUSION}

Our study provides a database for the physical profile, psychological profile, and HRQoL status of patients with COVID-19 at first month follow up. The HRQoL impairment of Chinese COVID-19 patients was significant. We propose early measures should be taken to prevent mental health problems, as well as initiation of a comprehensive program to assist COVID19 patients in recovering basic function. Furthermore, we encourage the biomedical research community to pursue longitudinal monitoring of neuropsychiatric symptoms and status. Further follow-up is needed to assess the HRQoL of COVID-19 patients.

\section{DATA AVAILABILITY STATEMENT}

The raw data supporting the conclusions of this article will be made available by the authors, without undue reservation.

\section{ETHICS STATEMENT}

The studies involving human participants were reviewed and approved by Wenzhou Medical University. Written informed consent to participate in this study was provided by the participants' legal guardian/next of kin.

\section{AUTHOR CONTRIBUTIONS}

K-YC, J-SZ, and X-KL conceived the study. K-YC, TL, and F-HG collected and analyzed the data. K-YC, J-SZ, and X-KL wrote the paper. All authors contributed to the article and approved the submitted version.

\section{FUNDING}

The study was partially supported by grants from China Academy of Engineering 2020-XY-88(2020-KYGG-04-02) and COVID-19 Emergency Response projects (No. ZY202002 and No. 2020-004).

\section{ACKNOWLEDGMENTS}

We thank all the patients for their cooperation and support in this research. 


\section{REFERENCES}

1. World Health Organization. Clinical management of severe acute respiratory infection when novel coronavirus (2019-nCoV) infection is suspected: interim guidance, 28 January 2020. World Health Organization (2020). https://apps. who.int/iris/handle/10665/330893

2. Huang C, Wang Y, Li X, Ren L, Zhao J, Hu Y, et al. Clinical features of patients infected with 2019 novel coronavirus in Wuhan, China. Lancet (2020) 395 (10223):497-506. doi: 10.1016/S0140-6736(20)30183-5

3. Richardson KM, Rothstein HR. Effects of occupational stress management intervention programs: a meta-analysis. J Occup Health Psychol (2008) 13 (1):69-93. doi: 10.1037/1076-8998.13.1.69

4. Asadi-Pooya AA, Simani L. Central nervous system manifestations of COVID-19: A systematic review. J Neurol Sci (2020) (1878-5883):116832. doi: 10.1016/j.jns.2020.116832

5. Bansal M. Cardiovascular disease and COVID-19. Diabetes Metab Syndr (2020) 14(3):247-50. doi: 10.1016/j.dsx.2020.03.013

6. Terpos E, Ntanasis-Stathopoulos I, Elalamy I, Kastritis E, Sergentanis TN, Politou M, et al. Hematological findings and complications of COVID-19. Am J Hematol (2020) 95(7):834-47. doi: 10.1002/ajh.25829

7. Bao Y, Sun Y, Meng S, Shi J, Lu L. 2019-nCoV epidemic: address mental health care to empower society. Lancet (2020) 395(10224):e37-8. doi: 10.1016/S0140-6736(20)30309-3

8. Tran BX, Ha GH, Nguyen LH, Vu GT, Hoang MT, Le HT, et al. Studies of Novel Coronavirus Disease 19 (COVID-19) Pandemic: A Global Analysis of Literature. Int J Environ Res Public Health (2020) 17(11):E4095. doi: 10.3390/ ijerph17114095

9. Gill TM, Feinstein AR. A critical appraisal of the quality of quality-of-life measurements. JAMA (1994) 272(8):619-26. doi: 10.1001/jama.272.8.619

10. Caballero T, Prior N. Burden of Illness and Quality-of-Life Measures in Angioedema Conditions. Immunol Allergy Clin North Am (2017) 37:597-616. doi: 10.1016/j.iac.2017.04.005

11. Lins L, Carvalho FM. SF-36 total score as a single measure of health-related quality of life: Scoping review. SAGE Open Med (2016) 4:1-12. doi: 10.1177/ 2050312116671725

12. Han Y, Liu Y, Zhou L, Chen E, Liu P, Pan X, et al. Epidemiological Assessment of Imported Coronavirus Disease 2019 (COVID-19) Cases in the Most Affected City Outside of Hubei Province, Wenzhou, China. JAMA Netw Open (2020) 3(4):e206785. doi: 10.1001/jamanetworkopen.2020.6785

13. Wu JT, Leung K, Leung GM. Nowcasting and forecasting the potential domestic and international spread of the $2019-\mathrm{nCoV}$ outbreak originating in Wuhan, China: a modelling study. Lancet (2020) 395:689-97. doi: 10.1016/ S0140-6736(20)30260-9

14. Jin YH, Cai L, Cheng ZS, Cheng H, Deng T, Fan YP, et al. A rapid advice guideline for the diagnosis and treatment of 2019 novel coronavirus (2019$\mathrm{nCoV}$ ) infected pneumonia (standard version). Mil Med Res (2020) 7:4. doi: 10.1186/s40779-020-0233-6

15. Li L, Wang H, Shen Y. Development and psychometric tests of a Chinese version of the SF-36 Health Survey Scales. Zhonghua Yu Fang Yi Xue Za Zhi (2002) 36(2):109-13. doi: 10.3760/j:issn:0253-9624.2002.02.011

16. Mishra GD, Hockey R, Dobson AJ. A comparison of SF-36 summary measures of physical and mental health for women across the life course. Qual Life Res (2014) 23(5):1515-21. doi: 10.1007/s11136-013-0586-3

17. Rui W, Cheng W, Ma XQ, Zhao YF, Yan XY, Jia H. Health-related quality of life in Chinese people: a population-based survey of five cities in China. Scand J Public Health (2011) 39(4):410-8. doi: 10.1177/1403494810395817
18. Li K, Wu J, Wu F, Guo D, Chen L, Fang Z, et al. The Clinical and Chest CT Features Associated With Severe and Critical COVID-19 Pneumonia. Invest Radiol (2020) 55(6):327-31. doi: 10.1097/RLI.0000000000000672

19. Wilder-Smith A, Freedman DO. Isolation, quarantine, social distancing and community containment: pivotal role for old-style public health measures in the novel coronavirus (2019-nCoV) outbreak. J Travel Med (2020) 27(2): taaa020. doi: $10.1093 / \mathrm{jtm} /$ taaa020

20. Wang CA, Pan R, Wan X, Tan Y, Xu L, Ho CS, et al. Immediate Psychological Responses and Associated Factors during the Initial Stage of the 2019 Coronavirus Disease (COVID-19) Epidemic among the General Population in China. Int J Environ Res Public Health (2020) 17:1729. doi: 10.3390/ ijerph17051729

21. Yao H, Chen JH, Xu YF. Patients with mental health disorders in the COVID19 epidemic. Lancet Psychiatry (2020) 7(4):e21. doi: 10.1016/S2215-0366(20) 30090-0

22. Baig AM, Khaleeq A, Ali U, Syeda H. Evidence of the COVID-19 Virus Targeting the CNS: Tissue Distribution, Host-Virus Interaction, and Proposed Neurotropic Mechanisms. ACS Chem Neurosci (2020) 11(7):9958. doi: 10.1021 /acschemneuro.0c00122

23. Ziegler CGK, Allon SJ, Nyquist SK, Mbano IM, Miao VN, Tzouanas CN, et al. SARS-CoV-2 Receptor ACE2 Is an Interferon-Stimulated Gene in Human Airway Epithelial Cells and Is Detected in Specific Cell Subsets across Tissues. Cell (2020) 181(5):1016-1035.e19. doi: 10.1016/j.cell.2020.04.035

24. Desforges M, Le Coupanec A, Dubeau P, Bourgouin A, Lajoie L, Dubé M, et al. Human Coronaviruses and Other Respiratory Viruses: Underestimated Opportunistic Pathogens of the Central Nervous System? Virus (2019) 12 (1):14. doi: 10.3390/v12010014

25. Liu Y, Lee DC, Li Y, Zhu W, Zhang R, Sui X, et al. Associations of Resistance Exercise with Cardiovascular Disease Morbidity and Mortality. Med Sci Sports Exercise (2019) 51(3):499-508. doi: 10.1249/MSS.0000000000001822

26. Ware JE KM. SF-36 physical and mental health summary scales: a manual for users of version 1. 2nd ed. Lincoln, RI: QualityMetric Incorportated (2005).

27. Kerr ZY, Thomas LC, Simon JE, McCrea M, Guskiewicz KM. Association Between History of Multiple Concussions and Health Outcomes Among Former College Football Players: 15-Year Follow-up From the NCAA Concussion Study (1999-2001). Am J Sports Med (2018) 46(7):1733-41. doi: $10.1177 / 0363546518765121$

28. Kerr ZY, DeFreese JD, Marshall SW. Current physical and mental health of former collegiate athletes. Orthop J Sports Med (2014) 2(8):2325967114544107. doi: $10.1177 / 2325967114544107$

29. Park SA-O. Pathways linking obesity to health-related quality of life. Qual Life Res (2017) 26(8):2209-18. doi: 10.1007/s11136-017-1565-x

30. Del Core MA, Ahn J, Wukich DK, Liu GT, Lalli T, VanPelt MD, et al. Gender Differences on SF-36 Patient-Reported Outcomes of Diabetic Foot Disease. Int J Lower Extrem Wounds (2018) 17(2):87-93. doi: 10.1177/1534734618774664

Conflict of Interest: The authors declare that the research was conducted in the absence of any commercial or financial relationships that could be construed as a potential conflict of interest.

Copyright (c) 2020 Chen, Li, Gong, Zhang and Li. This is an open-access article distributed under the terms of the Creative Commons Attribution License (CC BY). The use, distribution or reproduction in other forums is permitted, provided the original author(s) and the copyright owner(s) are credited and that the original publication in this journal is cited, in accordance with accepted academic practice. No use, distribution or reproduction is permitted which does not comply with these terms. 